\title{
O USO DA TAXA DO BDI (BONIFICAÇÕES E DESPESAS INDIRETAS) PARA A VERIFICAÇÃO DA EXEQÜIBILIDADE DOS PREÇOS DAS OBRAS PÚBLICAS
}

\author{
THE UTILIZATION OF THE BDI (BENEFITS AND INDIRECT \\ EXPENSES) TAX AS A PARAMETER TO ANALYSE THE \\ CONSISTENCE OF THE STATE OWNED CONSTRUCTION PRICES
}

\author{
Eudes Moacir Toscano Júnior, MSc. \\ Profissão: Auditor de Contas Públicas do Estado da Paraíba \\ Instituição:Controladoria Geral do Estado da Paraíba \\ Departamento: Núcleo de Auditoria \\ Endereço: Av. Epitácio Pessoa, 1457 - $5^{\circ}$ andar - Bairro dos Estados \\ CEP. 58.000-040 - João Pessoa - PB \\ Telefone: 83-2187741 \\ e-mail: biota@openline.com.br \\ Guilherme de Albuquerque Cavalcanti, Dr. \\ Profissão: Professor Adjunto \\ Instituição: Universidade Federal da Paraíba - UFPB \\ Departamento: Economia (Centro de Ciências Sociais Aplicadas) \\ Endereço: Cidade Universitária - Campus I \\ CEP: $58051-900$ \\ João Pessoa, PB. \\ Telefone:83-216-7287 \\ E-mail: cgedccsa.ufpb.br
}

\begin{abstract}
Resumo
O objetivo deste trabalho é analisar a exeqüibilidade dos preços das obras públicas, através da utilização da taxa do BDI - Bonificações e Despesas Indiretas - incremento percentual aplicado aos custos dos serviços de engenharia para a formatação de seus preços. A pesquisa procurou comparar os percentuais dos componentes do BDI de algumas obras licitadas pela Secretaria de Educação e Cultura do Estado da Paraíba, com os seus respectivos valores recomendados pela legislação aplicável e literatura especializada sobre o tema, a fim de levantar a hipótese de que os acréscimos e rescisões contratuais observados nos dados da pesquisa têm estreita relação com a imperfeita composição da taxa do BDI.
\end{abstract}

Palavras-chave: BDI, licitação, obras públicas.

\begin{abstract}
The purpose of this work is to analyze the consistency of State Owned Building Construction prices, through the utilization of the BDI (Benefits and Indirect Expenses) tax, - which is a percent increase applied to the costs of the engineering services so as to format its prices. The research aimed to compare the percentages of the BDI tax components of some constructions contracted by the Secretary of Education and Culture of the State of Paraíba, with its due values, recommended by the pertinent legislation and technical literature, in order to raise the hypothesis that the contractual increases and also failures observed during the study have a straight relation with the miscalculation of the BDI tax.
\end{abstract}




\section{O PROCESSO DE FORMAÇÃO DOS PREÇOS DE OBRAS CIVIS}

Tradicionalmente os preços formados para o mercado da construção civil são desenvolvidos a partir de uma metodologia bastante semelhante à utilizada pela indústria e pelo comércio quando confeccionam seus preços. Apropriados os custos diretos da produção, os custos indiretos e os custos vinculados à venda, o produtor adiciona uma taxa para cobrir a margem de lucro, e então chega ao preço. Contudo, enquanto que no comércio e na indústria os custos relativos à produção podem ser aferidos por apropriação, na construção civil nada disso está disponível na fase de orçamento das propostas de preços, e de forma imprópria, essa metodologia é utilizada similarmente como se as indústrias tivessem as mesmas características. Na construção civil, trabalha-se com custos orçados e com um "markup" paramétrico, que além do lucro engloba também alguns custos indiretos. A esse "markup" dáse o nome de BDI, Benefícios e Despesas Indiretas (ROCHA LIMA Jr., 1993) .

É justamente nessa incongruência entre a forma de apropriação dos custos na indústria tradicional e na indústria da construção civil, que reside o grande desafio da consistência dos preços ofertados nas licitações para obras e serviços de engenharia. Segundo Rocha Lima Jr. (1993, p. 07) "primeiramente, associar custos incorridos com orçamento para produção já implica na introdução de uma margem de incerteza elevada." Sendo assim, é crucial que no processo de formação dos preços de obras e serviços de engenharia, sejam previstos, com o maior grau de profissionalismo possível, todos os elementos que incorrerão direta e indiretamente na produção do serviço, com vistas a possibilitar, no momento de acréscimo da taxa do BDI, o mínimo grau do nível de incerteza citada pelo Professor Rocha Lima . 


\section{CARACTERÍSTICAS RECENTES DOS PREÇOS NAS OBRAS PÚBLICAS}

A experiência recente dos profissionais da área tem demonstrado que muitos dos preços ofertados em licitações públicas para a contratação de empresas de construção civil, têm apresentado seríssimas distorções no que se refere à perfeita previsão de todos os encargos e insumos, que os mesmos se propõem a cobrir. Parga (1995, p. 05) cita situações em que "Na ânsia de se obter novas oportunidades de trabalho, barreiras prudentes eram rompidas com conseqüências desastrosas para os envolvidos."

O Professor Rocha Lima Jr. (1993, p. 01), a respeito dessas distorções, também enfatiza que "muitas vezes as operações representam um salto no escuro, onde riscos não são nem reconhecidos e um padrão de incerteza domina a sua gestão."

Portanto, depreende-se dessas assertivas que dois são os pontos concorrentes para o problema da inconsistência dos preços ofertados em licitações de obras e serviços de engenharia. A ambição desenfreada para conseguir, a qualquer custo, um contrato público, e que às vezes leva o empreiteiro a ultrapassar a linha do bom senso, e a forma, até certo ponto amadora, de como os empreiteiros compõem os seus preços.

Essa situação de acomodação do setor empreiteiro é tão presente, que Rocha Lima Jr. (1993, p 03) enfatiza que, ultimamente, "A prática do Estado propor o preço pelo qual se dispõe a contratar obras, buscando que, dentro de um intervalo máximo de variação, os empreiteiros aceitem aderir a ele, é cada vez mais comum." Ou seja, quem realmente compõe o preço é o Estado. Dessa forma, ficam os empreiteiros sem "(...) conhecer melhor o preço, para, inclusive, ao contratar com sua estrutura aberta, criar condições suficientes para embasar reivindicações para cobrir, com mais margem, os desvios que caiam fora da zona de monitoramento, ou conhecer o impacto das ações do contratante na quebra da qualidade econô mica ou financeira do contrato." (ROCHA LIMA Jr. , 1993, p. 17) . 
É bastante claro, a partir das constatações retro, que urge um rigor técnico mais profundo, no que se refere à análise de compatibilidade dos preços ofertados em licitações para obras e serviços de engenharia com os preços praticados pelo mercado.

Mais especificamente com relação às licitações do tipo menor preço, é de se esperar que, ao avaliarmos as propostas financeiras e detectarmos o menor preço ofertado no certame, ele seja realmente o preço mais vantajoso para o Erário. Contudo, conforme destacam Velloso Borges et al (1997, p. 03), "Em processo licitatório busca-se o justo valor a certo contrato desejado pela Administração. O justo valor é o que se compatibiliza com a média dos preços praticados pelo mercado." Então, ao menor preço, não basta apenas ser simplesmente o menor, mas principalmente ser entre os menores preços o mais consistente sob o prisma do mercado, e assim, verdadeiramente, o mais vantajoso para a Administração. Defrontando-se com um preço excessivamente baixo, e em tese bastante interessante à Administração, os responsáveis em ratificar a exeqüibilidade desse preço devem promover diligências a fim de se adquirir a planilha de custos unitários dos serviços propostos pelo licitante, para efetuar um minucioso exame da compatibilidade desse determinado preço com os preços que estão, no momento, sendo praticados pelo mercado. (VELLOSO BORGES E OUTROS, 1997)

A sistemática da composição inconsistente dos preços de obras e serviços de engenharia postos em oferta nas licitações públicas é tão disseminada que, o Tribunal de Contas dos Municípios do Estado do Ceará assinala para as muitas ocasiões nas quais as empresas que vencem as licitações não cumprem com as obrigações sociais e outros encargos pertinentes à obra, justamente por utilizarem mão-de-obra contratada no local da mesma, empreitada por preço global com o mestre-de-obras e sem os devidos recolhimentos legais. (SOARES DA ROCHA et al, 1997). 
Dessa forma, tanto na insuficiência de insumos para arcar com a quantidade e a qualidade do serviço contratado, quanto na sonegação de tributos relacionados com a produção de serviços, encontram-se as artimanhas dos incontáveis "preços baixos", cotados em licitações de obras e serviços de engenharia. Esses preços são indubitavelmente baixos, contudo representam a possibilidade real de enormes prejuízos ao Erário quando são contratados e postos em prática no decorrer dos seus respectivos contratos. Muitas vezes Aditivos Contratuais são criados apenas para viabilizar a conclusão da obra, evitando-se o aumento do prejuízo já incorrido.

É com bastante propriedade que Soares da Rocha et al (1997, p. 15) esclarecem que “(...) a extrapolação do prazo de execução pode proporcionar prejuízos de ordem financeira, afetando o Erário municipal, pois em muitas vezes são criados Termos Aditivos de Complementação de Serviço ou Criação de Serviços Novos, por não se poder inserir um reajuste, ou então uma atualização monetária do saldo contratual, em virtude deste não ter sido contemplado no contrato."

\title{
ASPECTOS LEGAIS DOS PREÇOS DE OBRAS PÚBLICAS
}

O inciso II, do artigo 48 da Lei 8666/93, determina que serão consideradas desclassificadas de um certame licitatório:

\begin{abstract}
Art. $48^{\circ}-\S 2^{\circ}$ - as propostas com valor global superior ao limite estabelecido ou com preços manifestamente inexeqüiveis, assim considerados aqueles que não venham a ter demonstrado sua viabilidade através de documentação que comprove que os insumos são compatíveis com a execução do objeto do contrato, condições estas necessariamente especificadas no ato convocatório da licitação.(Grifo nosso).
\end{abstract}

Claramente nota-se a intenção do legislador de coibir a adjudicação do objeto de uma licitação de obras ou serviços de engenharia a um licitante com propostas financeiras imperfeitas, enfim, inconsistentes, no que tange à regularidade de seus preços. Portanto, 
conforme Tolosa Filho (2000, p. 28) afirma, "O preço, para que a Comissão de Licitação possa considerá-lo manifestamente inexeqüível, quando o objeto da licitação for do tipo menor preço, deve ter demonstrado em ata que os custos dos insumos e que os coeficientes de produtividade impedem que o proponente tenha condições de executar os serviços ou de fornecer o bem."

Trata-se de uma questão de análise financeira bastante criteriosa da proposta do licitante vencedor, quando esse apresenta um preço muito aquém dos praticados pelo mercado. O licitante tem de provar à Comissão de Licitação que os componentes do seu preço, inclusive a parcela do lucro, são compatíveis com os preços médios do mercado. (TOLOSA FILHO, 2000, grifo nosso).

Especificamente com relação à contratação de obras e serviços de engenharia pelo Estado, a declaração de inexeqüibilidade de preço passou a ter um argumento matemáticoestatístico, todavia ineficaz, com o acréscimo do parágrafo $1^{\circ}$, ao artigo 48 da Lei 8666/93, através da Lei 9648/98, originária da conversão da Medida Provisória 1531 e suas reedições, rezando, em suma, que serão consideradas inexequiíveis as propostas de preços que sejam inferiores a 70\% do menor dos seguintes valores: Média Aritmética dos valores das propostas superiores a 50\% do orçamento da Administração ou o valor orçado pela Administração.

Embora tenha sido inegavelmente oportuno a introdução desse novo parâmetro estatístico para evitar a ocorrência da contratação com preços inexeqüíveis, o que se verifica na prática, claramente nos relatórios de julgamento das Comissões de Licitação, é que esses parâmetros não se prestam para servir de limites para a consistência mercadológica dos preços de empreitadas. Os cálculos efetuados, com base nessas determinações legais para encontrar o limite da exeqüibilidade, sempre redundam em valores que se encontram assustadoramente abaixo dos patamares de preços praticados pelo mercado da construção civil. Por conseguinte, 
esse limite acaba, invariavelmente, declarando que, todos os preços participantes da licitação que estejam acima dele são consistentes, isto é, compatíveis com aquele mercado.

Com a ausência de um parâmetro verdadeiramente eficaz, que auxilie as Comissões de Licitação para a tomada de decisão quanto ao que se possa entender por preços manifestamente inexeqüíveis, uma série de estudos e pesquisas tem sido desenvolvida pelos atores que do lado do Estado encontram-se envolvidos nesse processo, com o intuito de amenizar os efeitos nefastos que podem advir de contratações com preços operacionalmente insuficientes, mas, sob o ponto de vista legal, viáveis.

Assim exposto, é proposição deste trabalho utilizar a rotina para a composição da taxa do BDI (Benefícios e Despesas Indiretas) de obras civis, consagrada pela literatura pertinente ao tema e a partir daí procurar atingir os seguintes objetivos:

a) Geral: analisar o grau de compatibilidade entre os valores de alguns dos componentes do BDI dos preços ofertados nas licitações de obras e serviços de engenharia, realizadas pelo Estado, através da $\mathrm{SEC} / \mathrm{PB}$, e os seus respectivos valores recomendados pela literatura especializada e legislação aplicável.

b) Específicos: i) verificar se os valores dos componentes da taxa do BDI, analisados na pesquisa, apresentam equivalência com os valores recomendados pelos autores abordados na pesquisa;

ii) procurar identificar quais os componentes do BDI dos preços analisados na pesquisa que mais acentuam as diferenças entre os valores recomendados pela literatura especializada e legislação aplicável e;

iii) estabelecer a hipótese de que as incompatibilidades entre os valores dos componentes observados e os seus respectivos valores recomendados são elementos motivadores de rescisões e excessivos aditivos contratuais. 
Com os valores dos componentes do BDI recomendados pelos autores abordados na pesquisa, será montada uma taxa de BDI que encerrará encargos mínimos e funcionará como parâmetro último de exeqüibilidade de preços. Dessa forma, essa taxa acusará de inexeqüível todas as taxas de BDI que por ventura estiverem abaixo dela e, por conseguinte, os preços formados a partir dessas taxas. Nossa convicção se baseia no fato de que segundo Rocha Lima Jr. (1993, p. 17):

(...) os mercados tendem a homogeneizar certos comportamentos, com elasticidade relativamente curta, a partir dos confrontos entre empresas para angariar seus espaços na competição. Isto indica que, em torno de certos patamares médios, deverão ter as empresas seus custos de gerenciamento próximo, sob pena, para aquelas que estiverem muito acima, de só poder competir comprometendo margem de resultado.

Por fim, o estudo, que será desenvolvido, envidará aferir a consistência dos valores de alguns dos componentes da taxa do BDI e tentará analisar criteriosamente com a confrontação desses valores, com os seus respectivos montantes recomendados pela literatura que será pesquisada, quais são os mínimos valores que devem ser considerados na composição da taxa do BDI (Bonificações e Despesas Indiretas), para que essa taxa possa servir de mecanismo de verificação da exeqüibilidade dos preços das obras públicas.

Em última análise, o presente trabalho almeja instaurar, nos órgãos de controle do Estado, a necessidade de uma discussão mais premente em torno da formação dos preços das obras públicas, com vistas a desenvolver mecanismos de análises mais criteriosos, para o efetivo julgamento da exeqüibilidade desses preços.

\section{FONTES E INSTRUMENTOS}

Para a elaboração deste estudo, foram coletados dados referentes à composição da taxa de BDI (Bonificações e Despesas Indiretas) diretamente com os empreiteiros que 
participaram dos convites e das tomadas de preços realizadas pela Comissão Especial de Licitação da Secretaria da Educação e Cultura do Estado da Paraíba em 1998 e em 1999.

Através de um dispositivo contido nos editais das licitações efetuadas nos anos abrangidos pela pesquisa, foi possível a obtenção de informações fidedignas acerca do processo de formação dos preços dessas empresas de construção civil, via composição da taxa do BDI, que de outra forma não teria alcançado o mesmo êxito, em virtude da resistência natural dos empresários em fornecer informações sobre suas estruturas de custo.

A ausência ou a não apresentação do detalhamento do BDI ensejaria, na forma do edital, a desclassificação do licitante. Portanto, o preenchimento da ficha padronizada do detalhamento do BDI era condição sine qua non para prosseguimento na licitação.

\section{TRATAMENTO DOS DADOS}

Para a coleta dos dados da pesquisa, foi utilizado um modelo de questionário padronizado, no qual os entrevistados deveriam explicitar, em termos percentuais, relativamente, a participação no preço proposto, os montantes referentes aos componentes da Administração Local, dos Impostos e Taxas, da Administração Central, das Despesas Financeiras e dos Benefícios que foram os elementos utilizados para a aferição da compatibilidade da taxa de BDI (Bonificações e Despesas Indiretas) entre os preços ofertados nas licitações objeto da presente análise, e os valores recomendados pela literatura especializada, ou ainda exigidos pela legislação aplicável para alguns desses mesmos componentes. Da coleta dos dados foram gerados os quadros abaixo: 


\section{QUADRO 01: VALORES PERCENTUAIS DOS COMPONENTES DO BDI - LICITAÇÕES OCORRIDAS EM 1998.}

\begin{tabular}{|c|c|c|c|c|c|c|}
\hline \multirow{2}{*}{$\begin{array}{c}\text { EMPRESA } \\
\text { VENCEDO- } \\
\text { RA POR } \\
\text { LICITAÇÃO }\end{array}$} & \multicolumn{6}{|c|}{$\begin{array}{c}\text { ITENS DA COMPOSIÇÃO DO BDI } \\
\text { EM PERCENTAGENS DO PREÇO PROPOSTO (\%) }\end{array}$} \\
\hline & $\begin{array}{l}\text { ADM. } \\
\text { LOCAL }\end{array}$ & $\begin{array}{l}\text { IMPOSTOS E } \\
\text { TAXAS }\end{array}$ & $\begin{array}{c}\text { ADM. } \\
\text { CENTRAL }\end{array}$ & $\begin{array}{c}\text { DESPESAS } \\
\text { FINANCEIRAS }\end{array}$ & BENEFÍCIOS & $\begin{array}{l}\text { TOTAL } \\
\text { DO BDI }\end{array}$ \\
\hline$A-T P 01 / 98$ & 2,05 & 6,25 & 0,45 & 0,05 & 1,20 & 10,00 \\
\hline В -TP 02/98 & 0,80 & 6,28 & 1,00 & 0,20 & 1,72 & 10,00 \\
\hline C- СС $02 / 98$ & 0,80 & 6,28 & 1,00 & 0,20 & 1,72 & 10,00 \\
\hline$D-C C \quad 03 / 98$ & 3,85 & 6,65 & 0,50 & 0,00 & 4,00 & 15,00 \\
\hline E-CC 06/98 & 2,35 & 5,65 & 1,50 & 1,00 & 1,50 & 12,00 \\
\hline C-CC 07/98 & 2,00 & 5,15 & 0,50 & 0,30 & 2,05 & 10,00 \\
\hline A -CC 09/98 & 2,65 & 5,15 & 0,65 & 0,05 & 1,50 & 10,00 \\
\hline$F-C C 010 / 98$ & 8,20 & 6,25 & 2,75 & 1,00 & 1,80 & 20,00 \\
\hline$G-C C 011 / 98$ & 4,80 & 5,15 & 1,20 & 0,00 & 0,85 & 12,00 \\
\hline H-СС 012/98 & 3,60 & 4,65 & 0,50 & 0,25 & 1,00 & 10,00 \\
\hline$A-C C 016 / 98$ & 2,05 & 6,25 & 0,45 & 0,05 & 1,20 & 10,00 \\
\hline I- CC 017/98 & 2,00 & 5,15 & 0,25 & 0,00 & 2,60 & 10,00 \\
\hline$H-C C ~ 022 / 98$ & 3,60 & 4,65 & 0,50 & 0,25 & 1,00 & 10,00 \\
\hline$J-C C ~ 023 / 98$ & 6,40 & 7,85 & 2,50 & 1,25 & 3,60 & 20,00 \\
\hline В -CC 024/98 & 0,80 & 6,28 & 1,00 & 0,20 & 1,72 & 10,00 \\
\hline$K-C C ~ 025 / 98$ & 4,74 & 7,15 & 1,00 & 0,50 & 7,61 & 21,00 \\
\hline$J-C C 026 / 98$ & 6,40 & 5,65 & 2,50 & 1,25 & 4,20 & 20,00 \\
\hline$F-C C 028 / 98$ & 8,20 & 6,25 & 2,75 & 1,00 & 1,80 & 20,00 \\
\hline
\end{tabular}

Fonte: CEL/SEC/PB (1998).

QUADRO 02: VALORES PERCENTUAIS DOS COMPONENTES DO BDI LICITAÇÕES OCORRIDAS EM 1999

\begin{tabular}{|c|c|c|c|c|c|c|}
\hline \multirow{2}{*}{$\begin{array}{c}\text { EMPRESA } \\
\text { VENCEDO- } \\
\text { RA POR } \\
\text { LICITAÇÃO }\end{array}$} & \multicolumn{6}{|c|}{$\begin{array}{c}\text { ITENS DA COMPOSIÇÃO DO BDI } \\
\text { EM PERCENTAGENS DO PREÇO PROPOSTO }(\%)\end{array}$} \\
\hline & $\begin{aligned} \text { ADM. } \\
\text { LOCAL }\end{aligned}$ & $\begin{array}{l}\text { IMPOSTOS E } \\
\text { TAXAS }\end{array}$ & $\begin{array}{c}\text { ADM. } \\
\text { CENTRAL }\end{array}$ & $\begin{array}{c}\text { DESPESAS } \\
\text { FINANCEIRAS }\end{array}$ & BENEFÍCIOS & $\begin{array}{l}\text { TOTAL } \\
\text { DO BDI }\end{array}$ \\
\hline L-TP 01/99 & 1,75 & 4,60 & 0,30 & 0,05 & 1,20 & 10,00 \\
\hline$M-C C ~ 03 / 99$ & 3,35 & 5,65 & 0,40 & 0,50 & 4,10 & 14,00 \\
\hline$N-C C 05 / 99$ & 0,80 & 6,28 & 1,00 & 0,20 & 1,72 & 10,00 \\
\hline A-CС 07/99 & 3,55 & 4,60 & 0,65 & 0,35 & 0,85 & 10,00 \\
\hline$A-C C 08 / 99$ & 3,55 & 4,60 & 0,65 & 0,35 & 0,85 & 10,00 \\
\hline$O-C C 011 / 99$ & 3,97 & 5,61 & 0,50 & 0,00 & 1,40 & 11,50 \\
\hline$P-C C 012 / 99$ & 3,50 & 4,65 & 1,25 & 0,40 & 0,20 & 10,00 \\
\hline$Q-C C 015 / 99$ & 2,00 & 6,75 & 0,25 & 0,25 & 1,00 & 10,00 \\
\hline В - СС 016/99 & 1,00 & 6,65 & 1,00 & 0,00 & 1,35 & 10,00 \\
\hline
\end{tabular}

Fonte: CEL/SEC/PB (1999)

Da análise dos valores apresentados pelas empresas licitantes para os componentes do BDI (Bonificação e Despesas Indiretas) por ocasião das licitações alvo do presente estudo, constata-se, à primeira vista, a insuficiente carga tributária que é considerada pelas empresas para efeito da composição da taxa do BDI de suas propostas de preços. De 
acordo com o SISTEMA INTEGRADO DE CONSTRUÇÕES E CONTROLE DE OBRAS SINCO do PROGRAMA PARAÍBA DE QUALIDADE E CONTROLE TOTAL, a carga tributária para serviços dessa natureza, à época da realização do presente estudo, deveria estar entre $9,83 \%$ e $11,83 \%$ do preço formatado para a proposta de execução do empreendimento.(VINAGRE NEIVA et al, 2000) Segundo o SINCO, a carga tributária a ser computada para obras e serviços de engenharia deve considerar os seguintes tributos:

\section{QUADRO 03: CARGA TRIBUTÁRIA INCIDENTE NAS OBRAS PÚBLICAS REALIZADAS NO ESTADO DA PARAÍBA}

\begin{tabular}{c|cc}
\hline TIPO DE IMPOSTO & ALÍQUOTA (\%) & BASE DE CÁLCULO \\
\hline IMPOSTO DE RENDA & 1,20 & $(8 \% \times 15 \%)$ sobre o faturamento da obra \\
CONTRIBUIÇÃO SOCIAL & 1,08 & $(12 \% \times 9 \%)$ sobre o faturamento da obra \\
COFINS & 3,00 & sobre o faturamento da obra \\
P.I.S. & 0,65 & sobre o faturamento da obra \\
I.S.S. & $2,00 \mathrm{~A} 4,00$ & sobre o faturamento da obra \\
CPMF & 0,30 & sobre o faturamento da obra \\
PROPENE (Dec. Est. 13817/91) & 1,60 & $(2 \%$ x $80 \%)$ sobre o faturamento da obra \\
TOT. DACARGA TRIBUTÁRIA & $9,83 \mathrm{~A} 11,83$ & sobre o faturamento da obra \\
\hline
\end{tabular}

Fonte: SINCO/SEC. DA ADM./PB (2000)

Outro ponto bastante interessante, sob o ponto de vista do percentual dos componentes do BDI apresentados pelos licitantes, diz respeito ao montante dos componentes benefícios e despesas financeiras. Vinagre Neiva et al (2000) afirmam que afora os casos em que o contratante adianta um volume razoável de dinheiro ao contratado, a empreiteira invariavelmente acaba atuando como um banco, pois ela empresta dinheiro ao contratante, no início do contrato, sob forma de materiais e serviços e obtém reembolso apenas após a primeira medição. $\mathrm{O}$ contratado deixa de aplicar o capital de giro no mercado financeiro para tocar o empreendimento. Portanto, essa perda de juros deverá ser contabilizada na formação do preço a ser proposto para a execução da obra ou do serviço. Bezerra da Silva (2001) chega a recomendar que uma reserva de $1,5 \%$ a $10,0 \%$ do preço de execução dos serviços deve estar separada para cobrir a despesa financeira gerada pelo financiamento da obra. Da análise dos dados da pesquisa, não se observa a ocorrência do percentual mínimo recomendado por 
Bezerra da Silva em nenhuma das licitações, ocorrendo apenas o percentual de 1,25\% para o montante das despesas financeiras em duas das licitações acompanhadas em 1998.

Já com relação ao percentual dos benefícios declarados pelos licitantes como suficientes para a remuneração pela execução dos serviços, constata-se que em apenas uma das licitações realizadas em 1998, houve um percentual acima do teto mínimo de 5\%, apontado, em recente artigo apresentado no site PINIWEB (2002), como patamar razoável para a taxa de lucratividade das empresas do setor da construção civil.

Além desses percentuais paramétricos e legais, apontados pelos autores citados para os gastos com despesas financeiras com a parcela dos benefícios e com os impostos, há ainda, com relação aos demais componentes da taxa do BDI, outros valores percentuais recomendados pelos pesquisadores do assunto, que se diferenciam bruscamente dos valores percentuais obtidos no presente estudo, através da aplicação dos modelos de detalhamento da composição da taxa do BDI. Para ilustração da afirmação retro, pode-se considerar como exemplos os percentuais de $5 \%$ a $15 \%$ para os componentes administração central e administração local. Esses são os valores percentuais recomendados por Bezerra da Silva (2001) para que os custos referentes a essas estruturas não extrapolem as expectativas planejadas na fase de orçamento dos serviços, e venham a corroer parte do percentual estipulado para o componente benefícios, inviabilizando assim, os ganhos com a execução da obra. Observando-se os quadros 01 e 02 neste capítulo, constata-se que para o componente administração local, nas licitações acompanhadas em 1998, apenas em quatro delas houve um percentual acima do mínimo recomendado por Bezerra da Silva (2001), enquanto que para as licitações acompanhadas em 1999, nenhuma delas apresentou percentual para esse componente, acima ou mesmo igual ao recomendado pelo referido autor. Já para o componente administração geral observa-se que, tanto para as licitações acompanhadas em 
1998 como para as de 1999, nenhuma delas apresentou percentuais compatíveis com o mínimo de 5\% referenciado acima.

\section{ADITIVOS E RESCISÕES VERIFICADOS NA PESQUISA}

Após a coleta dos dados relativos à composição da taxa do BDI, procedeurse o acompanhamento dos contratos que foram gerados pelas licitações observadas na pesquisa. Com esse acompanhamento, pretendeu-se observar quais seriam, dentre os preços que foram propostos e aceitos nas licitações como preços exeqüíveis, aqueles que possibilitariam a execução regular dos contratos das obras, sem que houvesse a necessidade de aditivos ou mesmo de rescisões contratuais. Assim, após a conclusão dos contratos de reforma e/ou ampliação das escolas que foram objeto das licitações acompanhadas na pesquisa, construíram-se os seguintes quadros:

\section{QUADRO 04: SITUAÇÃO DOS VALORES CONTRATUAIS AO FIM DOS CONTRATOS LICITAÇÕES OCORRIDAS EM 1998.}

\begin{tabular}{l|c|c|c|c}
\hline LICITAÇÃO & $\begin{array}{c}\text { PREÇO ESTIMADO } \\
(\mathbf{R} \mathbf{\$})\end{array}$ & $\begin{array}{c}\text { PREÇO VENCEDOR } \\
(\mathbf{R} \mathbf{})\end{array}$ & $\begin{array}{c}\text { ADITIVO } \\
\text { APLICADO AO } \\
\text { CONTRATO (\%) }\end{array}$ & $\begin{array}{c}\text { PREÇO FINAL } \\
\text { APÓS O } \\
\text { ADTIVO }\end{array}$ \\
\hline (RP)
\end{tabular}

Fonte: CEL/SEC/PB (1998) 


\section{QUADRO 05: SITUAÇÃO DOS VALORES CONTRATUAIS AO FIM DOS CONTRATOS LICITAÇÕES OCORRIDAS EM 1999.}

\begin{tabular}{c|c|c|c|c}
\hline LICITAÇÃO & $\begin{array}{c}\text { PREÇO ESTIMADO } \\
\text { (R\$) }\end{array}$ & $\begin{array}{c}\text { PREÇO VENCEDOR } \\
\mathbf{( R \$ )}\end{array}$ & $\begin{array}{c}\text { ADITIVO } \\
\text { APLICADO AO } \\
\text { CONTRATO }(\%)\end{array}$ & $\begin{array}{c}\text { PREÇO FINAL } \\
\text { APÓS O ADITIVO } \\
(\mathbf{R} \$)\end{array}$ \\
\hline TP $001 / 99$ & $191.676,78$ & $152.029,52$ & 12,93 & 171.691 .82 \\
C.C $003 / 99$ & $55.869,14$ & $45.821,79$ & 31,60 & $60.283,13$ \\
C.C $005 / 99$ & $52.289,43$ & $37.891,23$ & 24,07 & $47.010,13$ \\
C.C $007 / 99$ & $248.930,04$ & $177.952,26$ & 0,00 & RESCINDIDO \\
C.C $008 / 99$ & $24.283,45$ & $18.231,14$ & 0,00 & RESCINDIDO \\
C.C $011 / 99$ & $60.448,25$ & $44.729,44$ & 39,60 & $62.454,21$ \\
C.C $012 / 99$ & $29.999,98$ & $23.382,23$ & 0,00 & RESCINDIDO \\
C.C $015 / 99$ & $8.155,06$ & $7.145,06$ & 23,60 & $8.829,40$ \\
C.C $016 / 99$ & $91.978,22$ & $69.119,67$ & 48,30 & $102.519,01$ \\
\hline
\end{tabular}

Fonte: CEL/SEC/PB (1999)

Observa-se, nos quadros 04 e 05 retro, que apenas o contrato da licitação cartaconvite 02/98 não sofreu reajuste, sendo concluído pelo preço proposto na fase de licitação. Com exceção dessa licitação, todas as demais tiveram os seus preços vencedores alterados para maior através de aditivos contratuais, ou tiveram seus contratos rescindidos, como é o caso das licitações na modalidade carta-convite de números 07/99, 08/99 e 12/99. Para as licitações analisadas em 1998, 94\% delas sofreram aditivos contratuais para viabilizarem a conclusão dos serviços, e para as licitações analisadas em 1999, descontadas as que tiveram seus contratos rescindidos, todas as outras licitações, isto é, 100\% delas sofreram aditivos contratuais.

\section{RECOMENDAÇÕES}

De todas as incompatibilidades encontradas na confrontação dos dados da pesquisa com os valores que são recomendados pelos autores abordados no trabalho, os valores percentuais do componente Impostos e Taxas são os que mais objetivamente podem ser considerados como seriamente desequilibrados e passíveis de impugnação, haja vista a insuficiente carga tributária que, tacitamente, é declarada pelos licitantes em seus 
detalhamentos das taxas do BDI de suas propostas de preços. Os valores paramétricos recomendados por Bezerra da Silva (2001) e PINIWEB (2002) são valores que efetivamente devem ser considerados pertinentes à luz da experiência e fidedignidade de suas fontes, contudo não podem ser indiscriminadamente aplicáveis a todas estruturas empresariais, sob pena de não levarmos em conta todas as peculiaridades administrativas das empresas, além da tipificação das obras, fatores que até então vimos evidenciando como cruciais para a determinação do percentual a ser aplicado a taxa do BDI.

Independente do tipo da obra ou da estrutura da empresa, já que no presente trabalho as empresas são todas de pequeno porte e assim optantes do benefício da Tributação pelo Lucro Presumido, o que as coloca no rol das empresas cujas receitas anuais não superam os R $\$ 12.000 .000,00$ (GITMAN, 1997), a carga tributária mínima a ser considerada para a execução dos serviços é, então, aquela estipulada no capítulo anterior pelo SINCO.

O Estatuto das Licitações e Contratos Públicos estabelece em seu artigo 29 que, uma vez exigido no edital do certame, as empresas licitantes devem comprovar suas regularidades fiscais perante as Fazendas Federal, Estadual e Municipal, além de regularidade perante a Seguridade Social e o Fundo de Garantia por Tempo de Serviço. Dessa forma, não parece sensato que, uma vez preocupada com a idoneidade fiscal das empresas licitantes na fase inicial da licitação, a Administração permita que uma determinada empresa que declara não estar computando em seus preços a carga tributária, a qual incidirá na execução do contrato advindo da licitação, tenha aceitado sua proposta de preços sem que essa ilegalidade seja devidamente impugnada. Ademais, a própria Lei de Licitações e Contratos em seu $\S 3^{\circ}$, do artigo 44, exprime a preocupação em vedar a aceitação de propostas com preços global ou unitários simbólicos, irrisórios ou de valor zero, incompatíveis com os preços dos insumos e salários de mercado, acrescidos de respectivos encargos. Além disso, a citada Lei ainda determina, em seu artigo 55, inciso XII, que em todos os contratos públicos deve constar 
cláusula que obrigue o contratado a manter, durante toda execução do contrato, compatibilidade com as obrigações por ele assumidas e todas as condições de habilitação e qualificação exigidas no edital da licitação.

Com base nesses fatos e com vistas a subsidiar o processo decisório da escolha da proposta mais vantajosa à Administração, a exigência em todos os editais de licitação de obras, principalmente nas modalidades Carta-Convite e Tomadas de Preços, da apresentação do detalhamento da taxa do BDI, como elemento auxiliar na verificação da compatibilidade dos componentes dessa taxa com as exigências legais quanto à tributação do futuro serviço, seria uma importante providência. A ineficácia do dispositivo instituído no $\S 1^{\circ}$, do artigo 48 da Lei 8666/93 para a decretação de inexeqüibilidade de preços, no caso de obras e serviços de engenharia, suscita a aplicação de outro parâmetro mínimo, igualmente legal, para a verificação da consistência de um preço de uma obra pública.

Nesse norte, a constatação de que o componente Impostos e Taxas da composição da taxa do BDI deve, no mínimo, ser da ordem de 9,91\% do faturamento da obra, considerando que o aumento da alíquota da CPMF de 0,30\% para 0,38\% elevou a carga tributária mínima calculada pelo SINCO de $9,83 \%$ para $9,91 \%$, tornando a aceitação de um preço proposto na base de uma taxa de BDI de $10 \%$ bastante incoerente. A consideração de que um preço nessa base é aceitável, implica na admissão de que os demais componentes do BDI terão de ser cobertos por um percentual do faturamento do serviço menor que $0,1 \%$. Claramente insuficiente.

A pesquisa evidenciou as grandes diferenças que ocorrem entre os valores percentuais recomendados pela literatura e legislação aplicável para os componentes da taxa do BDI, e os valores desses componentes obtidos na coleta dos dados. Essas diferenças podem ter uma estreita relação com os níveis de aditivos contratuais e até mesmo rescisões de contrato que foram observados no decorrer das obras adjudicadas aos vencedores das 
licitações em análise. Embora não haja comprovação que essas diferenças percentuais sejam as únicas motivadoras dos aditivos e rescisões verificados, nem de quanto seria a sua influência para o quadro. De toda sorte, resta a confirmação que, após todo o trabalho desenvolvido, uma taxa de BDI da ordem de $10 \%$ é seguramente suficiente apenas para a liquidação dos tributos incidentes na obra ou no serviço de engenharia, e insuficiente para a execução regular de um contrato de uma obra ou serviço de engenharia. Uma taxa de BDI, na base de $10 \%$, poderia ser declarada como inconsistente, sob o argumento da cobertura de todos os insumos e encargos necessários a execução legal e regular de uma obra pública, e se constituiria num legítimo e legal parâmetro mínimo suplementar, ao que estipula a legislação aplicável, para a verificação da exeqüibilidade dos preços das obras públicas.

\section{REFERÊNCIAS BIBLIOGRAFICAS}

BEZERRA DA SILVA, Mozart. Olho vivo no orçamento. Revista Construção Mercado, São Paulo, n. 1, p. 40 - 46, ago. 2001.

BRASIL. Lei Federal $\mathrm{n}^{\circ}$ 8.666, de 21 de junho de 1993. Estabelece normas gerais sobre licitações e contratos administrativos pertinentes a obras, serviços (inclusive de publicidade), compras, alienações e locações no âmbito dos Poderes da União, dos Estados, do Distrito federal e dos Municípios.

Lei Federal 9.648, de 27 de maio de 1998. Altera dispositivos das leis n ${ }^{\circ} 3.890-\mathrm{A}$, de 25 de abril de $1961, \mathrm{n}^{\circ} 8.666$, de 21 de junho de $1993, \mathrm{n}^{\circ} 8.987$, de 13 de fevereiro de 1995, $\mathrm{n}^{\circ} 9.074$, de 07 de julho de 1995, $\mathrm{n}^{\circ}$ 9.427, de 26 de dezembro de 1996, e autoriza o Poder Executivo a promover a reestruturação das Centrais Elétricas Brasileiras- ELETROBRÁS e das suas subsidiárias, e dá outras providências.

GITMAN, Lawrence J. Princípios de Administração Financeira. 7. ed. São Paulo: editora HABRA Ltda ., 1997.

L. VELLOSO BORGES, Ana Silvia et al. Licitação de Obras e Serviços de Engenharia. In: II Simpósio sobre Auditorias de Obras Públicas, 1997, Recife - 24 a 27 de novembro .

PARGA, Pedro. Cálculo do Preço de Venda na construção civil. Rio de Janeiro: Pini, 1995. PINIWEB. Caminho do Lucro? Disponível em: http://www.piniweb.com/revista/construção. Acesso em 07 de janeiro de 2002.

ROCHA LIMA JÚNIOR, João da. O BDI na formação de preço de obras empreitadas. Revista Politécnica, São Paulo, v. 90, n . 208, p. 79-83, jan./abr., 1993. 
SOARES DA ROCHA, Márcio e outros. Irregularidades de maior incidência em Auditorias de Obras Públicas Municipais. In: II Simpósio sobre Auditorias de Obras Públicas. 1997, Recife - 24 a 27 de novembro.

TOLOSA Filho, Benedito de. O Preço: fator Determinante na Licitação. L \& C, ano III, $\mathrm{n}^{\circ}$ 21 , p . 26 - 29 , Mar. 2000.

VINAGRE NEIVA, Ana Amélia e outros . Composição das Taxas de Leis sociais e BDI. Programa Paraíba de Qualidade e Controle Total - Sistema Integrado de Construções e Controle de Obras - SINCO ; João Pessoa: 2000. 